\title{
CONTRIBUIÇÕES DA CULTURA, IMAGINAÇÃO E ARTE PARA A FORMAÇÃO DOCENTE
}

\author{
Célia Maria de Castro* \\ Marcel Mano** \\ Sueli Ferreira ${ }^{* * *}$
}

\section{RESUMO}

Neste trabalho refletimos acerca das relações entre cultura, imaginação, arte e formação docente. Ao compreender o currículo escolar como artefato sociocultural, inferimos que as diferentes práticas culturais vivenciadas pelos professores fora da escola também constituem os saberes docentes. Nesta perspectiva, enfocamos resultados de pesquisas que discutem hábitos e frequência de professores da educação básica relacionados a espaços expositivos de artes visuais, espetáculos de dança e teatro, concertos e cinema, e os fatores (materiais e imateriais) que dificultam a precária inserção de docentes no circuito organizado da arte. Sem a pretensão de indicarmos soluções para temáticas tão complexas, apontamos a formação estética como fundamental à prática pedagógica e propomos uma reflexão sobre questões ainda pouco exploradas nos estudos sobre formação de professores para a educação básica.

Palavras-chave: Formação docente. Formação estética. Currículo. Cultura. Imaginação.

\footnotetext{
* Doutora em Educação. Professora do Programa de Pós Graduação em Educação Universidade de Uberaba (UNIUBE).E-mail: celia.mca@gmail.com

** Doutor em Ciências Sociais. Professor do Instituto de Ciências Sociais da Universidade Federal de Uberlândia (UFU). E-mail: marcelmano@fafcs.ufu.br

*** Doutora em Educação pela Universidade Estadual de Campinas (UNICAMP). E-mail: sknox@uol.com.br
} 


\begin{abstract}
In this paper we reflect on the relationships among culture, imagination, art and educational formation. Understanding the school curriculum as a sociocultural artifact, we infer that the different cultural practices experienced by the teachers out of the school environment also constitute educational knowledge. From this perspective, we focus on results of researches that discuss the habits and the frequency to which teachers of basic education get exposed to visual art exhibitions, dance shows, theater, concerts and movies, and the factors (material and non-material) that hinder the precarious insertion of teachers in the organized circuit of the arts. Without the pretension of indicating solutions for such complex themes, we are pointing out aesthetic formation as fundamental to the pedagogical practice, and we propose a reflection on subjects still little explored in the studies about teachers' formation for the basic education.
\end{abstract}

Keywords: Educational formation. Aesthetic formation. Curriculum. Culture. Imagination.

A atuação profissional docente é constituída por elementos de ordem prática e teórica que são continuamente apropriados, interpretados, reinventados e construídos pelos sujeitos ao longo de suas trajetórias. Por isso, o ser professor não se constitui de um só golpe e tampouco tem uma forma acabada, mas, ao contrário, ele se faz num processo contínuo que se inicia muito antes e vai sempre além de sua vida universitária. Passa não só pelos cursos de formação e pela formação continuada em serviço, como também pelas interações sócio-históricas e culturais que o constroem como ser social.

A particularidade de sua atuação profissional cotidiana não é, assim, simplesmente a somatória das condições materiais e intelectuais presentes no processo de ensino-aprendizagem. Ela é, antes, a síntese singular de sua condição genérica humana. Como ser particular, o profissional da educação (como toda humanidade passada e presente) produz, reproduz, transforma e aperfeiçoa as condições de sua existência material e teórica por meio de uma ação consciente sobre o mundo, uma atividade teleológica entendida 
como ação e pensamento a um só tempo e que alguns tentam definir como práxis. Tomada deste ponto de vista, essa atividade unicamente humana não se refere a nenhum fenômeno individual ou reduzido a apenas uma dimensão, pois para realizar-se coloca em ação práticas singulares da espécie humana tais como as materiais (técnicas e instrumentos), as sociais (as relações interpessoais e institucionais) e as simbólicas (os valores e as visões de mundo).

Toda ontologia baseada na antropologia pode comprovar esses fatos. Quando consideramos as informações provenientes da paleoantropologia (por exemplo, LEAKEY, 1995; STANDFORD, 2004), é possível perceber como o longo processo de hominização e humanização da espécie humana foi, concomitantemente, um avanço biológico, material, racional e social. Na luta pela sobrevivência, nossos ancestrais se aperfeiçoaram simultaneamente nos mais diferentes aspectos da vida propriamente humana, tais como o andar bípede, a confecção de instrumentos, a organização social, a aquisição da fala e do pensamento simbólico etc. Não de maneira isolada ou privilegiada, estes foram os passos decisivos para se constituir uma humanidade oposta à animalidade. A partir daí, enquanto os animais permaneceriam em mundos fechados por continuarem a ter uma relação biologicamente fixa com o meio, a humanidade se abriria porque teria a condição de humanizar a natureza, transformando-a e nomeando-a, usando-a e representando-a, e por este processo, o homem humanizaria a si mesmo.

Quando a antropologia no século XIX pela primeira vez faz uso científico do conceito de cultura, ela o usava também na tentativa de marcar essa distinção básica entre a humanidade genérica e a animalidade, ou mais simplesmente, entre natureza e cultura. A respeito disso se expressou Geertz (1978, p. 61) "[...] somos animais incompletos e inacabados que nos completamos e acabamos através da cultura [...]". Aprendida e apreendida, a cultura, princípio da humanização do homem, foi usada nesta primeira antropologia para fazer referência a um conjunto de procedimentos ou normas de pensar, agir e relacionar-se compartilhados e reconhecidos pelos sujeitos. Assim, enquanto os animais permaneceram imersos no universo biológico e natural, os homens criaram todo um mundo não biológico, artificial, do qual são produtores e produtos a um só tempo. 
É neste sentido que o conceito de cultura foi primeiramente identificado como todos os produtos resultantes do esforço conjugado das atividades materiais, sociais e simbólicas da existência humana; em uma palavra: o supraorgânico, tal com se expressou Kroeber (1952), ou tudo aquilo que o homem adquire enquanto membro de uma sociedade, como escreveu Tylor (1871). Nesse contexto, a escola, de forma tradicional, foi entendida como o espaço formal da educação e transmissão do corpo de conhecimentos, valores, ações, instrumentos, relações e interações exigidas pela vida em sociedade e que a antropologia, por muito tempo, deu o nome de cultura. Porém, tal qual se metamorfoseou o entendimento do papel ou função da escola, o conceito de cultura também se transformou no seu uso científico, possibilitando o vislumbre de novas relações entre a escola, a ação pedagógica e a cultura.

Aquela primeira definição genérica de cultura, cunhada na antropologia do século XIX, serviu de base para entender a marca distintiva de toda e qualquer vida social humana (a humanidade oposta à animalidade), mas, ao longo do tempo, deixou de ser operacional para se pensar a diversidade interna à própria humanidade. Quando as tendências evolucionistas e etnocêntricas do século XIX sucumbiram aos esforços que ao longo do século XX se empreenderam para compreender a lógica interna das culturas, a identidade européia, até então definida em contraste a uma suposta barbárie ou selvageria de todos os outros povos foi também questionada. Antes, povos atrasados ou primitivos. Agora, povos cujos padrões de comportamento, ação e pensamento fazem sentidos e que, mediante procedimentos antropológicos, podem ser traduzidos para membros de outras culturas. Ao penetrar no universo dos sentidos e dos significados subjacentes e imanentes a quaisquer culturas, a antropologia adentrava, então, numa nova forma de pensar a cultura, a identidade e a diversidade.

Desde a escola francesa de antropologia (Durkheim, Mauss e LéviStrauss), que primeiramente entendeu cultura como sendo primordialmente um código simbólico, esse conceito passou a ser interpretado como o conjunto de representações, sentidos e significados que cada grupo de seres humanos elabora e reelabora ao longo de sua história. Fenômeno unicamente humano, a cultura se refere, pois, à capacidade que os seres humanos têm de dar sentido e significado ao mundo, à natureza, à sociedade, 
a si, aos outros povos etc. E, como a realidade dos fatos nos mostra, cada grupo de seres humanos, em diferentes épocas e lugares, deu sentidos e significados diferentes a eventos e passagens da vida aparentemente semelhantes (THOMAZ, 1995), criando, nesse caminho, a identidade compartilhada e a diversidade. Posto nesses termos, à antropologia cabe, portanto, a interpretação dos diferentes códigos simbólicos que constituem as diversas identidades e culturas.

É de se ressaltar, no entanto, que essa transformação no conceito de cultura foi impulsionada em face do fracasso das pretensões das teorias da aculturação, quando imaginaram que o capitalismo global traria o fim das culturas. Contra essa sentença de morte, hoje já se sabe que as diferentes culturas são capazes de se apropriarem de elementos da sociedade envolvente, ressignificando-os a partir da lógica cultural pré-existente. Nisto há o que Sahlins (1990) chamou de uma "prática da estrutura", uma ordenação cultural da história. Porém, em um segundo momento, e isso que é importante na argumentação, essa prática da estrutura permite constituirse numa "estrutura da prática", na qual intervêm interesses muitas vezes conflitantes entre os agentes sociais envolvidos, permitindo não mais a reprodução da estrutura, mas a sua transformação, ao dar condições para os sujeitos reelaborarem os sentidos e significados do mundo e de suas ações. Por isso, de acordo com as referências de uma antropologia atual, a identidade e a cultura não são compostas por essências metafísicas ou entidades naturais ahistóricas, mas sim pelos aspectos contextuais, históricos e dinâmicos. Dessa forma, a antropologia considera que há neste jogo de significar e ressignificar não só uma dinâmica interna capaz de absorver e dirigir os rumos da mudança cultural, mas também um jogo de espelhos no qual o repertório de símbolos e, portanto, dos sentidos atribuídos ao real, estão sempre na condição de serem ressignificados pelo exercício das possibilidades do real. Seria isso, provavelmente, um elemento daquilo que Castells (2008) chamou de "identidade de projeto", a reorganização do mundo, de suas relações e das relações do homem com o mundo e consigo mesmo, por meio dos processos de reelaboração e invenção de novas modalidades de percepção, significação e ação.

Em sala de aula, continuamente o professor é o mediador entre o real imediato vivido por ele e por seus alunos fora do ambiente escolar (às 
vezes de forma diferenciada) e o real pensado por meio do conhecimento teórico. Inseridos no contexto sócio-histórico-cultural, o real imediato, a escola, o conhecimento e seus sujeitos podem, numa dialética pedagógica, partir do concreto ao pensado e voltar ao concreto como concreto-pensado, numa atitude que possibilita não só elaborar sínteses do pensamento e do próprio real, como também sínteses das diversas formas de possibilidades do real que a imaginação ativa.

\section{As intrínsecas relações entre imaginação e cultura}

A partir das ideias apresentadas na primeira parte deste trabalho e na perspectiva de concepções histórico-culturais do desenvolvimento humano, propomos análises e reflexões sobre as intrínsecas relações entre imaginação e cultura.

Por um espaço significativo de tempo, concepções racionalistas sobre a atividade psíquica da imaginação deixaram marcas nos estudos da mente humana, opondo imaginação à razão. Entretanto, razão e imaginação complementam-se e são necessárias à constituição da realidade. O pensamento científico - racional e consciente - banha-se na imaginação para avançar no que produz, e a imaginação se faz presente em todas as atividades criadoras, não apenas nas artísticas, mas também nas científicas e tecnológicas e como "fantasia cristalizada" nas atividades da vida cotidiana (VYGOTSKY, 1982).

Nenhum pensamento racional é possível sem a colaboração da imaginação, e esta, por sua vez, não prescinde de um pensamento realista. Ainda que não se confundam, "os dois agem como uma unidade", diz Vygotsky (1982).

$\mathrm{Na}$ perspectiva da psicologia histórico-cultural de Vygotsky a imaginação refere-se ao manejo de imagens e experiências armazenadas na memória para (re)criar ou (re)produzir algo que já existe, a fim de transformar a realidade e modificar o presente, projetando o ser humano para o futuro. A natureza da imaginação é, portanto, fundamentalmente social e a cultura, produto da imaginação e da criação humana.

A função psicológica da imaginação, conforme Vygotsky (1982), estabelece vínculos com a realidade de quatro diferentes formas. A primeira 
é a relação que toda elucubração estabelece com elementos extraídos da realidade e de experiências anteriores. Neste caso, a imaginação mantém relação direta com a experiência, donde podemos concluir que quanto mais ampla, variada e rica for a experiência acumulada, maior a criatividade.

A segunda forma de vínculo da função imaginativa com a realidade é a que ocorre indiretamente, quando a imaginação se pauta em produtos da fantasia ou em experiências históricas, sociais ou de outros indivíduos, o que amplia as possibilidades para imaginar, vez que o indivíduo não fica restrito a um repertório de experiências diretas.

A terceira forma de relação entre imaginação e realidade é a determinada por aspectos emocionais. Ou seja, o estado emocional presente nos processos criadores seleciona e combina determinados elementos da realidade para atender ao nosso estado interior de ânimo. O que, entretanto, não significa que a fantasia resulte exclusivamente de nossos sentimentos, ou que sentimentos provocados por ela possam ser "[...] efetivamente vivenciados pelo homem que os experimenta." (VYGOTSKY, 1982, p. 24).

Por fim, o quarto modo de relação entre imaginação e realidade decorre do fato de que o produto da imaginação passa a existir no mundo e a exercer influência na realidade já existente. O que resulta da fantasia "[...] passa a existir realmente no mundo e a influir sobre os demais objetos." (VYGOTSKY, 1982, p. 24). Ou seja, a imaginação retira da realidade elementos que, reelaborados, convertem-se em produtos materializados que retornam à realidade. E ao retornarem a ela "[...] trazem já consigo uma força ativa, nova, capaz de modificar essa mesma realidade, fechandose deste modo o círculo da atividade criadora da imaginação humana." $\mathrm{Ou}$ seja, a atividade criadora "[...] tem sempre longa história atrás de si. Ao que chamamos criação não costuma ser mais que um catastrófico parto, conseqüência de uma longa gestação.” (VYGOTSKY, 1982, p. 27 e 31).

Para a psicologia histórico-cultural, o produto criado pela imaginação resulta da inadaptação dos seres humanos à realidade existente. Tal inadaptação funciona como força motriz para dinamizar a atividade criadora responsável por materializar o que foi imaginado. Nessa perspectiva, pode-se afirmar que aqueles que estão adaptados à realidade e em relação harmônica com o mundo nada podem criar. Ou seja, nós, humanos, necessitamos, para criar, de condições materiais, psicológicas, 
e de um meio social propício ao processo de criação. A esse respeite diz Vygotsky (1982, p. 37-38):

Todo inventor, por genial que seja, é sempre produto de sua época e de seu ambiente. Sua obra criadora partirá dos níveis alcançados com anterioridade e se apoiará nas possibilidades que existem também fora dele. Por isso notamos estrita seqüência no desenvolvimento histórico da ciência e da técnica. Nenhum descobrimento, nenhuma invenção científica aparecem antes que se criem as condições materiais e psicológicas necessárias para seu surgimento. [...]. Isso mesmo explica a distribuição desproporcionada de inventores e inovadores nas diversas classes sociais. As classes privilegiadas têm dado uma porcentagem consideravelmente maior de criadores científicos, técnicos e artísticos por ter em suas mãos precisamente todas as condições necessárias para criar.

Se a imaginação é uma forma de atividade consciente e fundamental à atividade criadora que se manifesta nos mais diferentes aspectos da vida humana, e se a cultura é produto da imaginação e criação humana, então devemos perguntar: professores fazem uso da sua imaginação na docência? Incentivam seus alunos a empregarem a imaginação? Consideram o papel da fantasia na constituição do conhecimento? Compreendem o valor da arte para a formação humana?

\section{Formação cultural de professores}

As questões que fecham a segunda parte deste texto nos conduzem a Bourdieu e Passeron (1975), autores cujos estudos indicam que competências culturais e linguísticas próprias de dada classe social determinam o desempenho escolar. Com base neste pressuposto, e também no que afirma Vygotsky acerca das relações entre experiência e imaginação criativa, é possível supor que quanto maior e mais variado for o repertório cultural dos professores, mais numerosas e apropriadas serão as escolhas possíveis para mediar a construção de conhecimentos escolares. 
Com a virada cultural ${ }^{1}$ dos anos 80 , a cultura passa a ser tema relevante para os estudos em educação e central na teorização curricular. Ao discutir as relações entre currículo escolar e cultura, Tomás Tadeu da Silva (1999) ressalta esta como campo de disputa simbólica pela afirmação de significados. Dado o esmaecimento dos limites que antes demarcavam claramente as distinções entre conhecimento acadêmico e escolar e conhecimento cotidiano e da cultura de massa, Silva (1999) entende a pedagogia como cultura e a cultura como pedagogia. A pedagogia é cultura porque os conteúdos escolares são parte da cultura ${ }^{2}$; a cultura é pedagogia porque outras instituições, além da escola, também educam ainda que não pretendam, de forma explícita, ensinar, transmitem várias formas de conhecimento que contribuem para a formação de identidades e subjetividades.

Tal pensamento expressa o de autores representativos dos estudos culturais, tal como Stuart Hall, para quem a cultura perpassa tudo o que acontece em nossas vidas, bem como todas as representações dos acontecimentos que nela vivemos. Para este autor a cultura tem papel central na formação das identidades sociais:

O que denominamos "nossas identidades" poderia provavelmente ser melhor conceituado como as sedimentações através do tempo daquelas diferentes identificações ou posições que adotamos e procuramos "viver", como se viessem de dentro, mas que, sem dúvida, são ocasionadas por um conjunto especial de circunstâncias,

\footnotetext{
${ }^{1}$ A "virada cultural" começou a ser engendrada a partir da década de 1970, quando aspectos culturais do comportamento humano passam a ser o centro privilegiado do conhecimento histórico, que abandona antigos conceitos como luta de classes e civilização para privilegiar os valores de grupos particulares, em locais e períodos específicos. Nessa nova perspectiva de estudo, as distinções culturais - com sua dimensão simbólica e suas interpretações - se sobrepõem aos elementos políticos e econômicos.

${ }^{2}$ Ao discutir a relação entre cultura e educação, Jean-Claude Forquin (1993) afirma ser a cultura o conteúdo da educação; é por ela que se transmitem às novas gerações os conhecimentos, as competências, as instituições, os valores e os símbolos que se constituíram durante gerações e caracterizam dada comunidade humana, definida de maneira mais ou menos ampla e mais ou menos exclusiva.
} 
sentimentos, histórias e experiências únicas e peculiarmente nossas, como sujeitos individuais. Nossas identidades são, em resumo, formadas culturalmente (HALL, 1997, p. 26).

Ao enfatizar a "centralidade da cultura"3 no mundo contemporâneo Hall reconhece a necessidade de se considerarem as ações e experiências dos indivíduos nas análises dos fenômenos sociais. Assim, se nossas identidades são culturalmente formadas, como afirma Hall (1997), cabe perguntar: qual formação cultural constitui as identidades de professores? Que contribuições essa formação cultural traz para as suas práticas pedagógicas? Subjazem à mediação que realizam com o objetivo de promover a aprendizagem discente?

Enquanto sujeitos sócio-históricos, professores têm visões de mundo, valores, sentimentos, comportamentos e hábitos próprios, constituídos por um conjunto de experiências vivenciadas nos mais diferentes espaços sociais. Assim, estudos sobre as relações de docentes com a cultura são de grande relevância, porque permitem compreender dimensões da vida social que atuam de forma determinante nas suas práticas pedagógicas. Esta parece ser uma das preocupações de Tardif (2002, p. 9): "Quais são os saberes que servem de base ao ofício de professor? [...] Como esses saberes são adquiridos?". Para este autor, os saberes docentes provêm de várias fontes: da formação escolar, do contato com colegas mais experientes e de experiências pessoais vividas nos mais diferentes espaços sociais. Diante desta afirmação de Tardif, podemos perguntar: entre as experiências pessoais dos professores brasileiros que atuam na educação básica, estariam contempladas práticas de leitura, o hábito de frequentar museus e exposições de arte, salas de concerto, teatro e cinema, enfim, experiências que mobilizem a imaginação e a fantasia?

Se a subjetividade do professor se constitui, também, no contexto sociocultural, há que se considerar a dimensão estética desse contexto, pois, conforme Vygostsky (2004), o sensível e o artístico não podem ser desprezados quando se busca compreender os processos de constituição do ser humano.

\footnotetext{
3 Termo cunhado por Hall (1997) para explicar que a cultura é eminentemente interpelativa, constitutiva de nossas formas de ser, de viver, de compreender e de explicar o mundo.
} 
Ainda que muitos estudos destaquem os vínculos entre cultura e educação, poucos são os autores que, ao discutirem a problemática da formação de professores, apontam a importância das experiências estéticas para os processos de subjetivação e para a constituição da profissionalidade docente. Dentre eles, Imbernón (1994, p. 53) entende caber às instituições formadoras "[...] incorporar o interesse pela cultura em suas diversas manifestações e formas artísticas.". Na mesma direção aponta Kincheloe (1997, p. 72):

[...] arte e literatura imaginativa oferecem uma epistemologia alternativa, uma forma de conhecer que transcende as declarativas formas de conhecimento; os textos literários, de drama, de música e de pintura fortalecem o poder dos indivíduos para ver e ouvir além do nível superficial da vista e do som.

Dentre os autores brasileiros, Regina Garcia e Sônia Kramer são as que mais têm escrito sobre a importância das artes para a formação dos professores. Garcia (2000) discute a necessidade de se superar uma falsa dicotomia entre arte e conhecimento, enquanto Kramer (1998) lembra que, embora muitos educadores fundamentem-se em Vygotsky, a maioria desconhece ser a arte tema central em sua teoria. Também defende uma política de formação cultural que assegure aos professores o acesso às mais variadas formas de expressão artística - literatura, teatro, cinema, música - , por entender que a formação cultural "[...] é parte do processo de construção da cidadania, é direito de todos [...]” (KRAMER, 1998, p. 21). Informações sobre práticas culturais de professores da educação básica foram recolhidas em recente pesquisa sobre o perfil dos docentes brasileiros. Nela os pesquisadores argumentam:

[...] se a escola é concebida como centro de formação, é esperado que as atividades ligadas à cultura, como música, literatura, teatro, cinema, entre outras, sejam partes importantes do processo educativo. A prática educativa pode estar voltada não apenas para o trabalho, mas também para a formação da pessoa no sentido mais amplo, o que inclui a estética e o ético, entre outras dimensões da vida. Desse 
modo, além das análises sobre o consumo cultural dos professores, mais recentemente tem-se percebido a importância de se conhecer suas preferências e atividades culturais (UNESCO, 2004, p. 89).

Nessa pesquisa, as informações fora recolhidas por meio de questionário respondido por uma amostra representativa -5.000 professores - do universo constituído por docentes de escolas públicas e privadas das 27 unidades federativas do Brasil. Sobre a participação de professores em eventos e atividades culturais - museus, exposições, teatro, concertos de música erudita, cinema etc. - os dados são alarmantes: 14,8\% dos professores nunca foram a um museu; 8,6\% nunca visitaram uma exposição de artes visuais; $17,4 \%$ dos professores nunca foram ao teatro, $62,1 \%$ nunca assistiram a um concerto; $8,6 \%$ disseram nunca ir ao cinema.

Resultados de pesquissa (ALMEIDA, C.M.C; ALMEIDA, M.E.; CAMARGO; SILVA, 2007) desenvolvidas em duas cidades mineiras Uberaba e Uberlândia - corroboram os índices obtidos na pesquisa da UNESCO. Em uma amostra de 30\% do total de professores que atuam na educação básica destas duas cidades, o consumo de bens culturais é, também, bastante restrito. Apenas 4,2\% confirmaram frequentar museus com certa regularidade, enquanto 46,5\% informaram nunca ir e 48,9\% disseram que vão raramente. A frequência ao teatro, espetáculos de dança e concertos é ainda mais baixa: aproximadamente $70 \%$ afirmaram nunca ir ao teatro, a espetáculos de dança ou concertos. A frequência regular a salas de cinema é mais alta - aproximadamente $21 \%$-, mas ainda não animadora; $42,2 \%$ frequentam salas de cinema esporadicamente, enquanto $37,7 \%$ afirmaram que assistem aos filmes somente em casa.

Outra pesquisa, realizada em Goiânia (NOGUEIRA, 2008), também apresenta índices muito próximos aos obtidos na pesquisa nacional e na realizada em Minas Gerais. Assim, é possível concluir que a maior parte dos professores que atuam na educação básica não tem o hábito de frequentar museus e exposições de artes visuais, concertos, espetáculos de dança e teatro, bem como salas de cinema; suas experiências culturais não se distinguem das de seus alunos: com eles compartilham a mesma cultura de massa disseminada em âmbito mundial. Trata-se de uma constatação perturbadora, que nos leva a indagar: que contribuições os docentes podem 
oferecer aos discentes se seus repertórios de experiências estéticas são semelhantes?

Os baixos índices de consumo de bens culturais obtidos na pesquisa da UNESCO podem indicar que em muitos municípios brasileiros é pequena ou nula a oferta de eventos culturais (muitas cidades brasileiras não contam nem mesmo com uma sala de cinema). Não é o que ocorre em Uberaba, Uberlândia e Goiânia, cidades que oferecem uma razoável oferta de eventos culturais, muitos deles gratuitos. $\mathrm{O}$ fato de não terem o hábito de consumir outras formas de expressão da cultura que não as da indústria cultural decorre, segundo os professores, dos baixos salários e de intensas jornadas de trabalho:

Eu não tenho quase tempo livre, porque a educação me toma muito tempo. Quando eu chego em casa - eu trabalho dois períodos -, eu crio uma família de três filhos, sozinha. Tenho uma ajuda só da minha sogra para pagar a faculdade da minha filha mais velha, e o resto sou eu. Alimentação, saúde, vestuário... ainda bem que não pago aluguel. [...] Eu dobro turno, porque o salário não dá pra trabalhar um certo período e ficar em casa outro. Eu fico o tempo inteiro na escola, de 6 da manhã às 6 da tarde [...] à noite eu vou arrumar as minhas coisas de casa: vou lavar, passar, cozinhar e repor frutas, uma verdura que tá faltando. Agora, aos sábados e domingos eu assisto muitos filmes, porque o noivo da minha filha tem uma irmã que tem uma locadora. Então ele leva muitos DVDs, muitos filmes pra gente assistir. A gente assiste comendo pipoca, um refrigerante, sabe?

Como é que você vai ao cinema e paga $R \$ 9,00$ ? É barato, mas o professor não tem condição. Se você somar a ida ao cinema uma vez por semana, são $R \$ 40,00$ por mês! Para quem ganha um salário de $R \$ 620,00 \ldots$ Eu pago condomínio, água, telefone, tem que ter um carro pra poder ir trabalhar...

Mas há, também, indícios de que a frequência a determinados eventos culturais está relacionada ao nível de educação, profissão, localização domiciliar, e, principalmente, às transmissões familiares, conforme assinalou Bourdieu (1998). 
Essa semana eu fiquei sabendo, por acaso, dessa apresentação dentro de uma escola, não teve divulgação; conversando com uma aluna, ela me falou que todo sábado tem apresentação de teatro e que é só você levar um quilo de alimento não perecível. Esse ano, agora em setembro, tá acontecendo apresentações de segunda a quinta, o mês todo, no Teatro Rondon Pacheco e no Sesc, mas a gente nem fica sabendo...

Ah, primeiro, o teatro é distante da minha casa... Não sei te dizer, nunca me interessei, nunca tive esse hábito em criança, não me interesso muito. Não conheço ninguém que vai, que freqüente, nem que converse sobre nada disso. O meu meio social não me propicia a vontade de ir, e até o teatro daqui é meio devagar.

Ressalte-se, ainda, que a maioria das ações culturais com financiamento público está alocada no centro das grandes cidades e se destina a um público consumidor exigente e diferenciado que vive nas principais capitais do País, não atingindo muitos segmentos do mercado consumidor, de modo que "[...] as camadas de mais baixa renda [nas quais está incluída a grande maioria do professorado] estão mais expostas às pressões exógenas exercidas pela mídia, tanto regionalmente (nos pequenos municípios), quanto no interior do tecido urbano" (CAIADO, 2001, p. 65).

Se à escola cabe a responsabilidade de ampliar a dimensão expressiva e criativa dos alunos, familiarizando-os com um mundo cultural que não faz parte do cotidiano de suas vidas, é premente a necessidade de se implementar uma política que contemple a formação estética dos professores.

Não se trata de desqualificar a cultura de massa, mas de defender que os professores tenham acesso, também, a outras formas de expressão artística, além da cultura de massa, pois, como bem afirma Rouanet (1999), é preciso fugir de uma falsa polarização entre alta cultura e cultura de massa, mesmo porque, conforme Canclini (2000), as culturas estão cada vez mais híbridas. Esta é, também, a posição de Monique Nogueira (2008, p. 38): 
A idéia de formação cultural que defendo [para os professores] vai, portanto, além da dicotomia cultura popular - cultura erudita. Ir além não no sentido de ignorar as diferenças, mas sim de promover um processo de enriquecimento pessoal que abrace todo esse campo, que inclua tanto o conhecimento das práticas culturais locais quanto as obras-primas universais.

Osdiferentesuniversos de significadosculturaisqueincessantemente transitam na sociedade informacional (CASTELLS, 2008) não podem ser obviamente colocados numa escala ou hierarquização, mas devem ser dentro de uma visão intercultural - levados em conta no processo criativo dos sujeitos e nas mediações possíveis entre o vivido, o apreendido e o imaginado. Neste caminho, cabe aos professores reconhecerem as culturas locais das quais participam, juntamente com seus alunos, bem como levar para a sala de aula outros universos de significados para que possam ser confrontados, apropriados e reconstruídos.

Fatores sociais e culturais têm importância decisiva no processo de constituição de saberes docentes, funções psicológicas e mediação do conhecimento. Necessário se faz compreender, portanto, que professores constituem suas práticas pedagógicas a partir de seus lugares de origem, suas posições nos diferentes grupos sociais que integram e no interior da instituição escolar. Assim, suas práticas não apenas buscam atender às prescrições da cultura escolar, mas também expressam uma subjetividade produzida pela cultura vivida em sociedade.

Ao se concordar com os pontos de vista aqui expostos sobre cultura e imaginação, impossível não compreender a necessidade de conferir aos currículos de formação docente maior atenção às práticas de ordem estética. É importante reforçar: o contato com a arte extrapola o conhecimento específico das artes bem como possibilita aos alunos aprenderem muito mais do que os conhecimentos escolares podem ensinar-lhes.

Se professores da educação básica raramente lêem ou vão ao cinema, teatro, salas de concerto ou exposição de artes visuais como podemos esperar que sejam capazes de proporcionar aos seus alunos experiências estéticas que nunca passam "[...] sem deixar marcas em nosso comportamento [...]"? (VYGOTSKY, 2004, p. 234). Se as barreiras 
simbólicas são o fator preponderante que impede alguns segmentos da população, dentre eles os professores, de consumir determinados bens culturais, urge rever os currículos de formação para a docência, e, também, implementar políticas públicas voltadas para a formação cultural e criativa dos docentes. São medidas que, talvez, possam contribuir para que o professor possa reelaborar sentidos e significados do mundo e de suas ações para construir uma "identidade de projeto" (CASTELLS, 2008).

\section{Referências}

ALMEIDA, C. M. C. et al. Relatório Cientifico Final encaminhado ao CNPq. Uberaba: Conselho Nacional de Pesquisa, 2007. 147 p. Relatório de pesquisa.

BOURDIEU, P. Escritos de educação. Petrópolis: Vozes, 1998.

BOURDIEU, P.; PASSERON, J. C. A reprodução: elementos para uma teoria do sistema de ensino. Rio de Janeiro: Francisco Alves, 1975.

CAIADO, A. S. da C. O espaço da cultura; guia cultural do Estado de São Paulo. São Paulo em Perspectiva, v. 15, n.2, p. 55-65, abr./jun. 2001.

CANCLINI, N. G. Culturas híbridas: estratégias para entrar e sair da globalização. São Paulo: Edusp, 2000.

CASTELLS, M. A era da informação: economia, sociedade e cultura, vol 2. O poder da identidade. São Paulo: Paz e Terra, 2008.

FORQUIN, J. C. Escola e cultura: as bases sociais e epistemológicas do conhecimento escolar. Porto Alegre: Artes Médicas, 1993.

GARCIA, R. L. (Org.). Múltiplas linguagens na escola. Rio de Janeiro: DP\&A, 2000.

GEERTZ, C. A interpretação das culturas. Rio de Janeiro: Zahar, 1978.

HALL, S. A centralidade da cultura: notas sobre as revoluções culturais do nosso tempo. Educação \& Realidade, Porto Alegre, v. 22, n.2, p. 15-46, jul./dez. 1997.

IMBERNÓN, F. La formación del profesorado. Barcelona: Paidós, 1994. 
KINCHELOE, J. L. A formação do professor como compromisso político: mapeando o pós-moderno. Porto Alegre: Artes Médicas, 1997.

KRAMER, S. Por entre as pedras: arma e sonho na escola. 3. ed. São Paulo: Ática, 1998.

KROEBER, A L. The nature of culture. Chicago: Chicago University Press, 1952.

LEAKEY, R. A origem da espécie humana. Rio de Janeiro: Rocco, 1995.

LÉVI-STRAUSS, C. Totemismo hoje. Petrópolis: Vozes, 1975.

NOGUEIRA, M. A. Formação cultural de professores ou a arte da fuga. Goiânia: Editora UFG, 2008.

ROUANET, S. P. As razões do Iluminismo. São Paulo: Cia das Letras, 1999. SAHLINS, M. Ilhas de história. Rio de Janeiro: Zahar, 1990.

SILVA, T. T. da. Documentos de identidade. Uma introdução às teorias do currículo. Belo Horizonte: Autêntica, 1999.

STANDFORD, C. Como nos tornamos humanos. Rio de Janeiro: Campus, 2004.

TARDIF, M. Saberes docentes e formação profissional. 3. ed. Petrópolis: Vozes, 2002.

THOMAZ, O. R. A antropologia e o mundo contemporâneo: cultura e diversidade. In: GRUPIONI, L. D. B.; SILVA, A. L. da (Org.). A temática indigena na escola: novos subsídios para professores de $1^{\circ}$ e $2^{\circ}$ graus. Brasília: MEC/MARI/UNESCO, 1995.

TYLOR, E. Primitive culture. New York: Henry Holt, 1871. v.2.

PESQUISA NACIONAL UNESCO. Perfil dos professores brasileiros: o que fazem, o que pensam, o que almejam. São Paulo: Moderna, 2004.

VIGOSKII, L. S. La imaginación y el arte en la infancia. Madrid: Akal, 1982.

VYGOTSKY, L. S. Psicologia e Pedagogia. São Paulo: Martins Fontes, 2004.

Data de Registro: 20/01/2009

Data de Aceite: 18/08/2010 
